\title{
Structural, Morphological and Acetone Sensing Properties of Ga doped ZnO Thin Films by Spray Pyrolysis
}

\author{
E. U. Masumdara, M. A. Barote ${ }^{\mathrm{b} *}$ \\ A Thin Film Physics Laboratory, Department of Physics, Rajarshi Shahu \\ Mahavidyalaya - Latur-413512, Maharashtra, India. \\ ${ }^{\text {B }}$ Department of Physics, Azad college, Ausa-413520, Maharashtra, India. (*Corr. Author)
}

\begin{abstract}
The Ga doped $\mathrm{ZnO}$ thin films were deposited on preheated amorphous glass substrates using spray pyrolysis technique. The structural properties of Ga doped $\mathrm{ZnO}$ thin films produced by the spray pyrolysis method at $450{ }^{\circ} \mathrm{C}$ substrate temperature are studied. The films exhibit a dominant peak at $2 \theta=34.44$ corresponding to the $(002)$ plane of $\mathrm{ZnO}$. A uniform grain growth in all the film samples is observed from the SEM and TEM micrographs.
\end{abstract}

Keywords: Spray pyrolysis; Ga-doped ZnO films; structural properties, SEM.

\section{INTRODUCTION}

Ga-doped $\mathrm{ZnO}$ (GZO) has drawn attentions recently because it has some advantages over AZO. Whereas AZO and GZO TCOs have comparable electrical properties [1], Ga dopant is less reactive with oxygen compared with $\mathrm{Al}$ dopant meaning that it can function as better dopant within $\mathrm{ZnO}$ [2]. In addition, the Ga- O covalent bond length of $1.92 \mathrm{~A}^{\circ}$, which is smaller than that of $\mathrm{Zn}-\mathrm{O}\left(1.97 \mathrm{~A}^{\circ}\right)$, is expected to cause smaller deformation of $\mathrm{ZnO}$ lattice when $\mathrm{Ga} 3+$ ions substitute $\mathrm{Zn} 2+$ site in case of high doping concentration [3]. Concerning the use of $\mathrm{Ga}$ as the dopant to enhance electrical properties, it has been reported that resistivity of GZO films decreased with increasing film thickness where as the transmittance of films decreased as the film thickness increased [4]. On the practical side, increasing the thickness of the GZO TCO film would result in rising cost and reduced throughput. Further, as in the case of the AZO films, it would be possible to improve the electrical properties of GZO films by post-annealing treatment in hydrogen atmosphere [5-8].

\section{EXPERIMENTAL DETAILS}

In this investigation, the $\mathrm{ZnO}$ :Ga thin films were deposited on preheated amorphous glass substrates using $\mathrm{P}$ C controlled spray pyrolysis technique supplied by Holmark (Cochin, India). A solution of zinc acetate in a mixed solvent of $75 \%$ methanol and $25 \%$ double distilled water was used as a precursor. Compressed air was used as the carrier gas. The GZO films were deposited at optimized temperature of $450{ }^{\circ} \mathrm{C}$ by varying the gallium concentration form 1 to 5 at $\%$. The precursor solution was atomized into the fine droplets and carried to the preheated glass substrates.

XRD (Rigaku Mini- II) was used to analyze the crystalline orientation and the crystalline plane spacing of the films. The XRD measurements were performed in a standard $\theta-2 \theta$ scan using a $\mathrm{Cu} \mathrm{k} \alpha$ radiation $(\lambda=1.5406 \AA)$ over the range of 200 to 800 . The microscopic features were observed through a scanning electron microscope (JEOL-JSM-5600). The acetone sensing properites is studied at $573 \mathrm{~K}$.

\subsection{X-ray diffraction analysis 3.1 X-ray diffraction analysis}

The structural properties of $\mathrm{Ga}$ doped $\mathrm{ZnO}$ thin films produced by the spray pyrolysis method at $450{ }^{\circ} \mathrm{C}$ substrate temperature were investigated by XRD and the results for all doping levels of Ga are shown in Fig. 1. The XRD patterns of these samples are in good agreement with the JCPDS standard (No. 75-0576) data of wurtzite hexagonal $\mathrm{ZnO}$. As seen from Fig. 1, the films exhibit a dominant peak at $2 \theta=34.44$ corresponding to the (002) plane of $\mathrm{ZnO}$. However, weaker $\mathrm{ZnO}$ peaks like (100), (101), (103) and (004) are also observed, suggesting that during the material deposing some grains grow with another orientation [9]. Apart from $\mathrm{ZnO}$ characteristic peaks, no peaks that correspond to either gallium, zinc or their complex oxide could be detected. Similar results were also obtained by T. Prasad Rao [10]. This observation suggests that the film do not have any phase segregation or secondary phase formation. Meanwhile, it was apparent that 


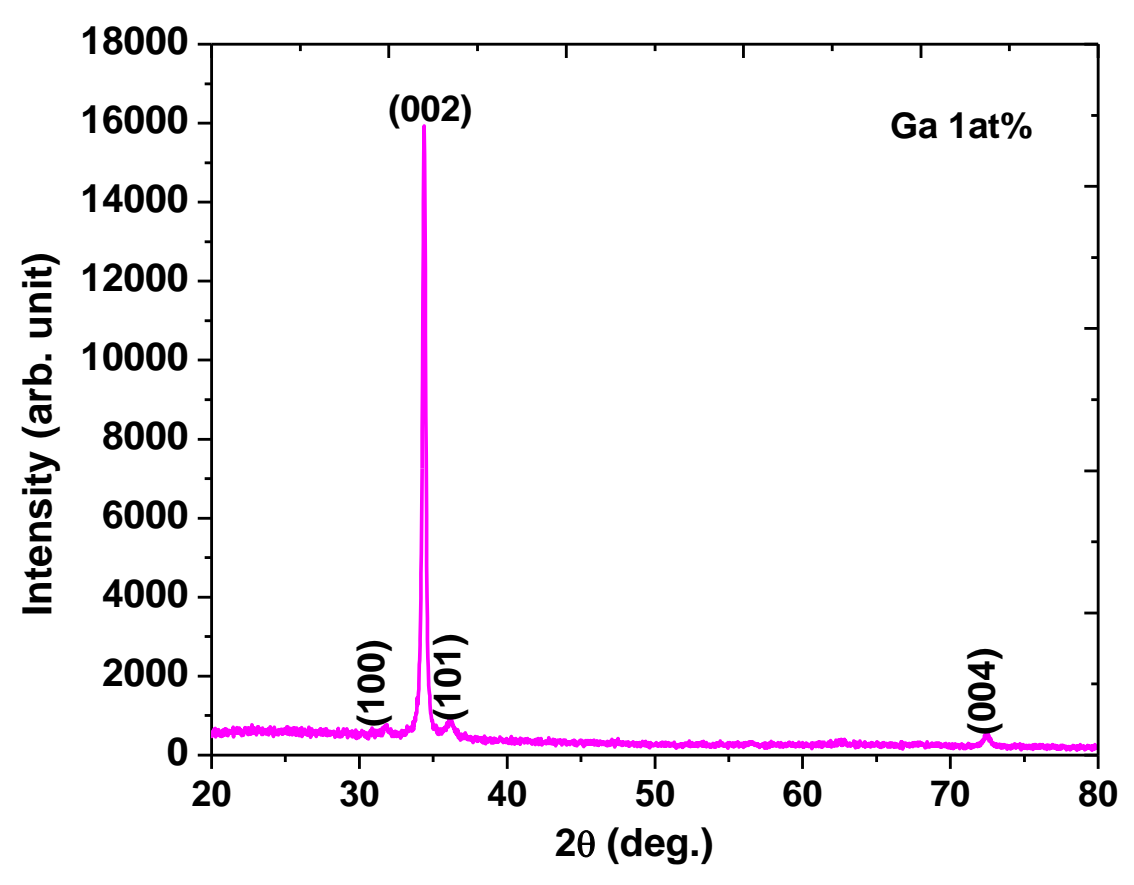

(a)

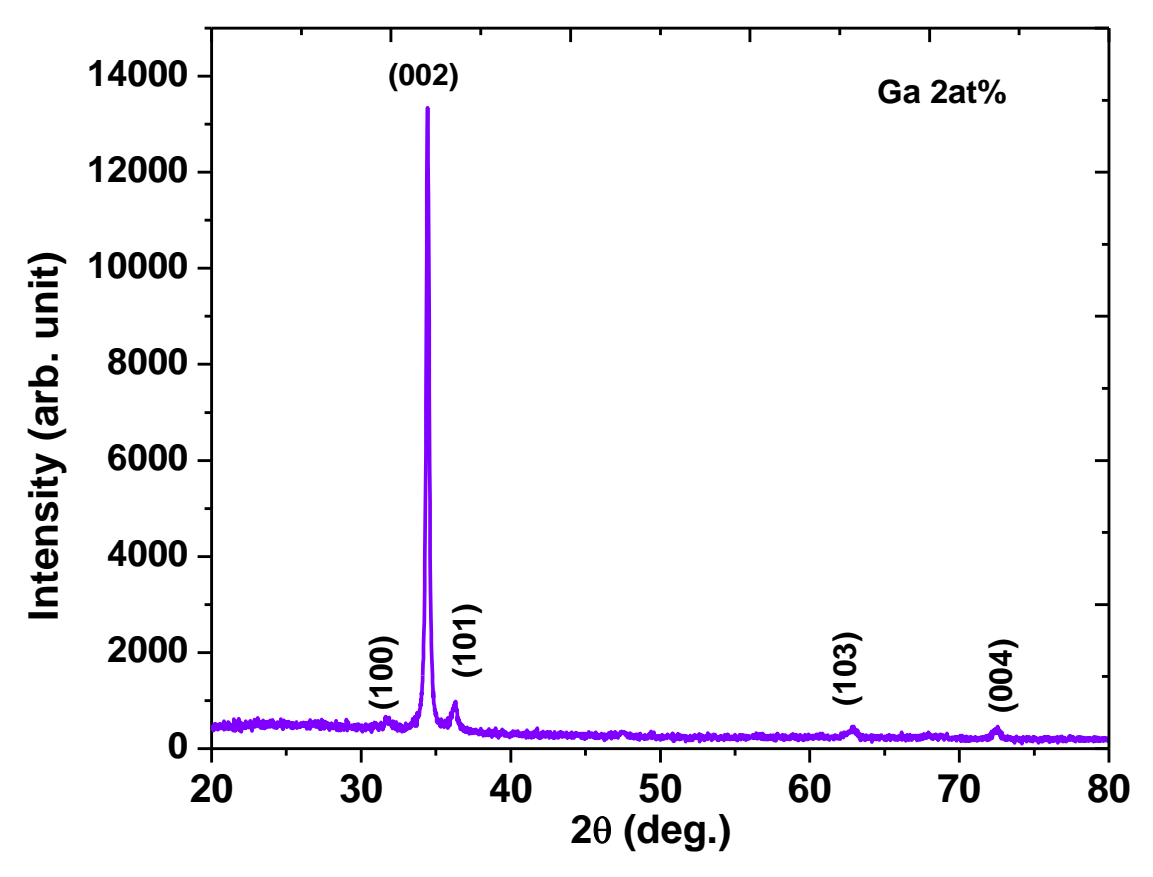

(b) 


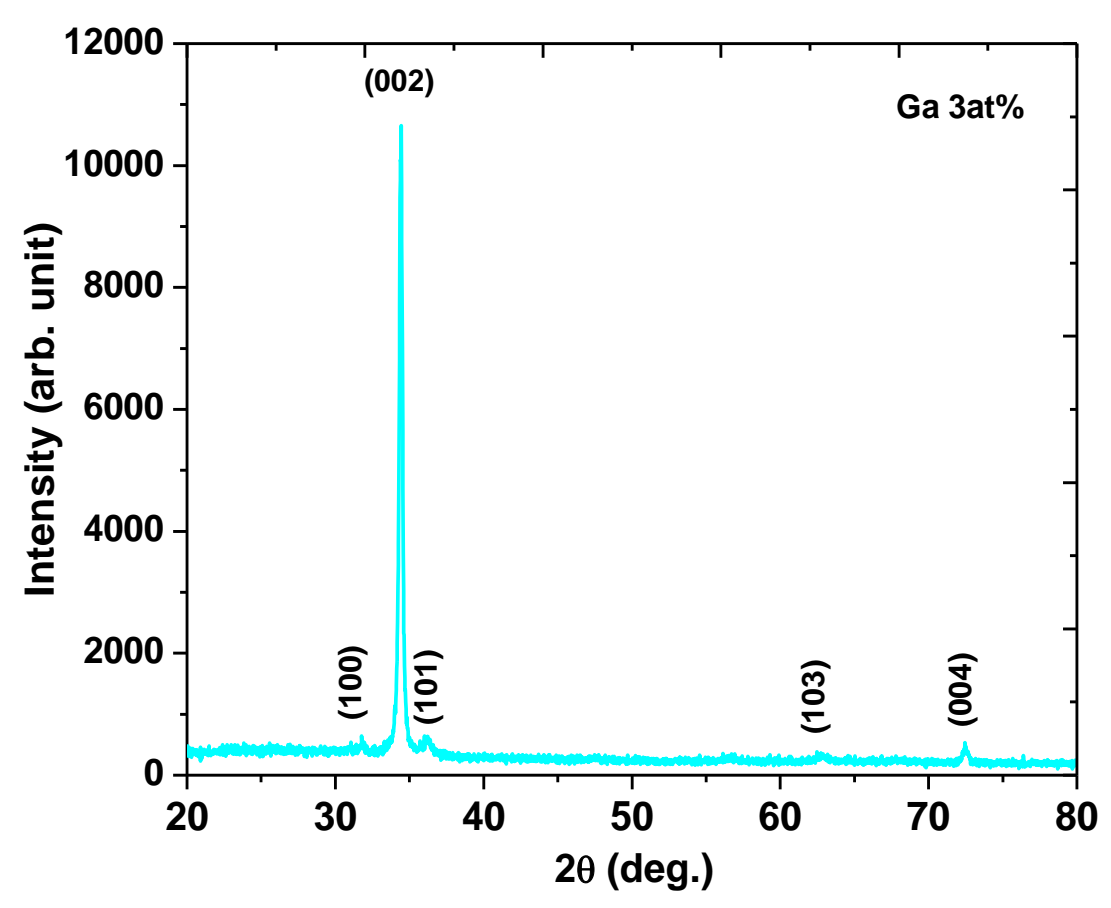

(c)

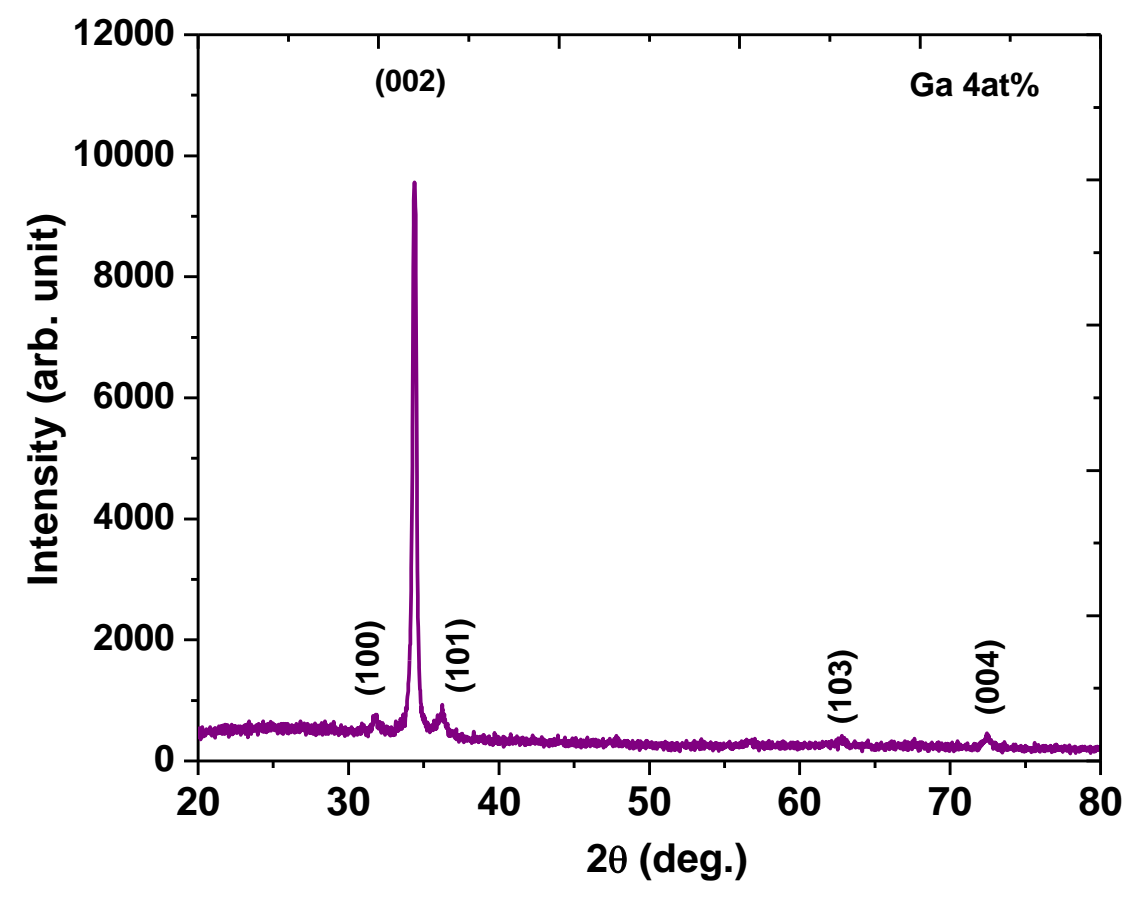

(d) 


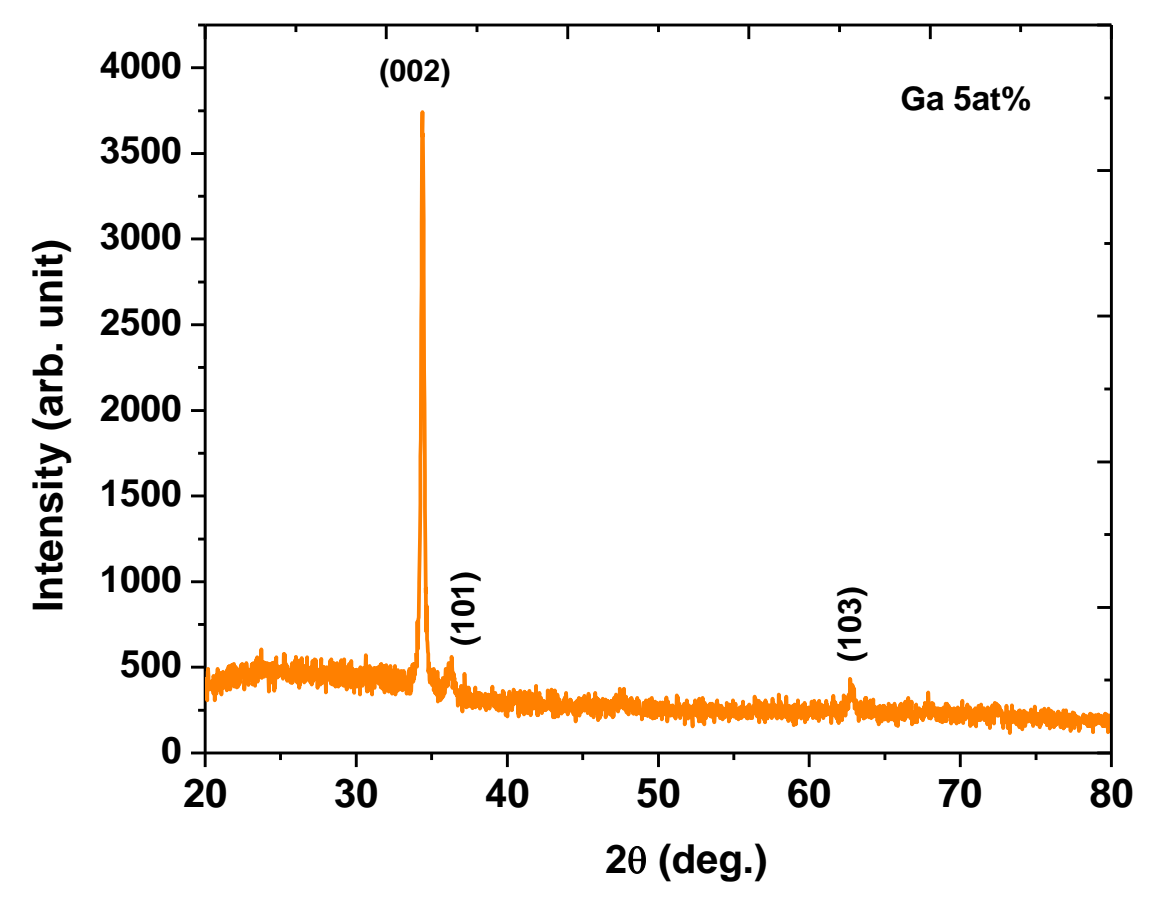

(e)

Figure 1: X-ray diffraction spectrum for the $\mathrm{ZnO}: \mathrm{Ga}$ films with different $\mathrm{Ga}$ at $\%$.

intensity of (002) diffraction peak decreased and the full width at half maximum (FWHM) of (002) peak decreased with increase in $\mathrm{Ga}$ concentration, indicating that the more the $\mathrm{Ga}$ concentration in $\mathrm{ZnO}$ films the worse the crystal quality. This might be due to the lattice disorder and strain induced by interstitial $\mathrm{Ga}$ atoms of the substitution of $\mathrm{Ga}$ for $\mathrm{Zn}$.

The average crystallite size for (002) peak has been calculated using Deby-Sherrer's equation [11]. It is observed that as $\mathrm{Ga}$ doping increases the crystallite size decreased.

\subsection{Surface morphological studies}

The two-dimensional surface morphologies of asdeposited GZO thin films were carried out using SEM

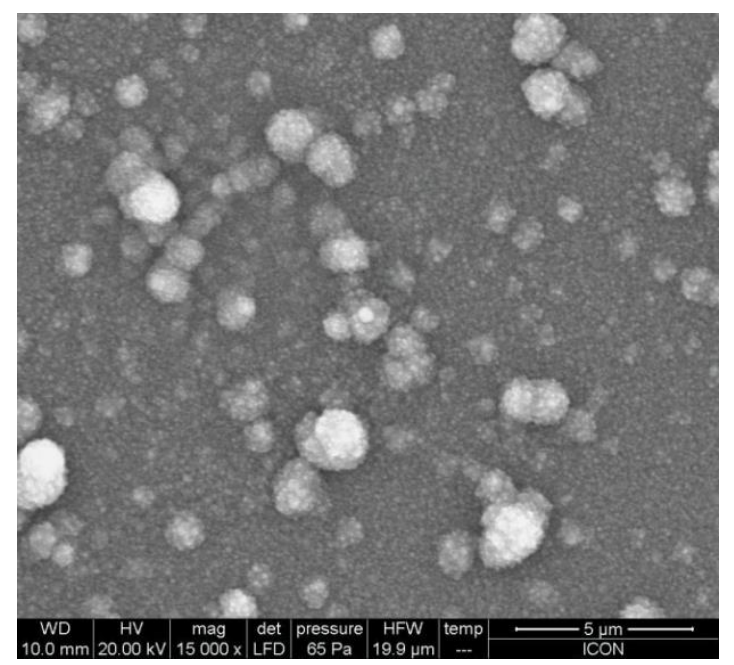

$(1 \mathrm{at} \%)$ images are shown in Fig. 2. A uniform grain growth in all the film samples is observed from the SEM micrographs. It is also observed that grains are small and distributed uniformly throughout the surface. The uniformity and compactness presented by the films is a result of the specific deposition and solution conditions. In this case, the surface is covered by round and small-size grains, and seems to be a smoother and more uniform surface, whereas, films with a higher content of $\mathrm{Ga}$ show an irregular surface, which is covered by different size grains and some big features that seems to be agglomerates of smaller-grains. As Ga doping concentration increases, a

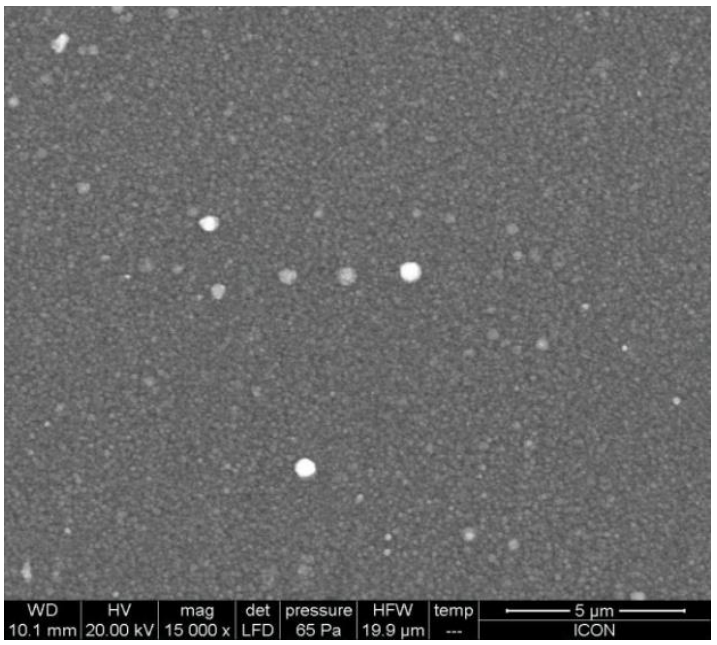

(3at\%) 


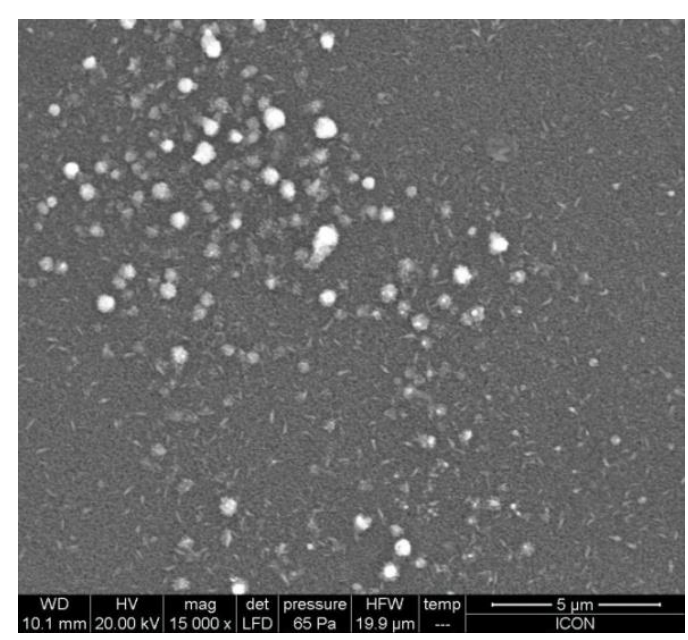

(5at\%)

Figure 2: SEM micrographs of the GZO films at various Ga at\%.

gradual decrease in grain size occurred due to an increasing number of nucleation centers during incorporation of the dopant into the host material [12].

Fig. 3 displays the surface morphology of the corresponding $\mathrm{ZnO}: \mathrm{Ga}$ thin films revealed by AFM. Although it is impossible to give a direct measure about the actual grain size from the AFM images, the results do exhibit apparent evolution in film grain morphologies with increasing $\mathrm{Ga} \%$. Since the films were grown on glass substrates and no epitaxial relation was expected, these phenomena might be understood as a direct consequence of surface diffusion enabled three-dimensional grain growth [13-14]. As seen from the AFM images the surface roughness increases as dopant concentration $\mathrm{Ga}$ increases from $1 \%$ to $3 \%$ and after increase in $\mathrm{Ga}$ concentration roughness decreases.

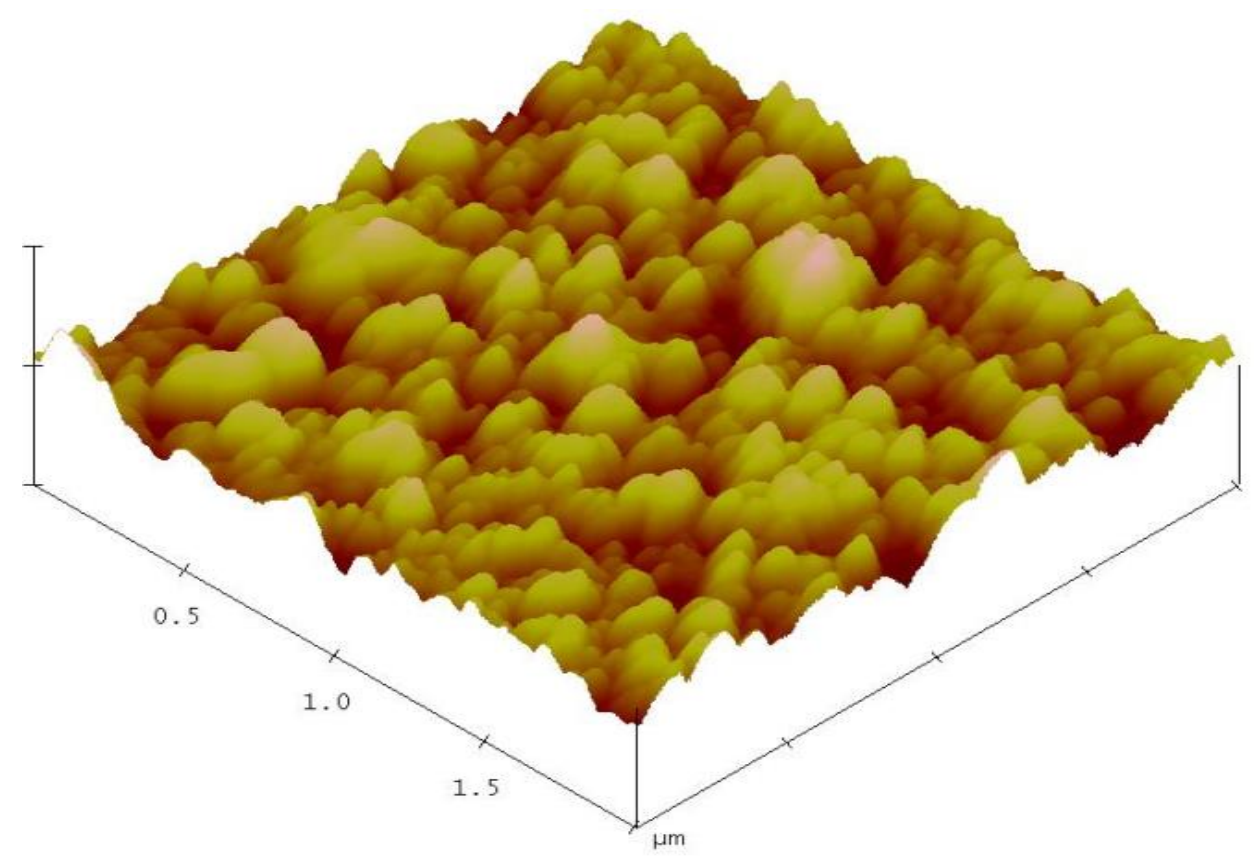

3D AFM image of GZO (1\% Ga) 


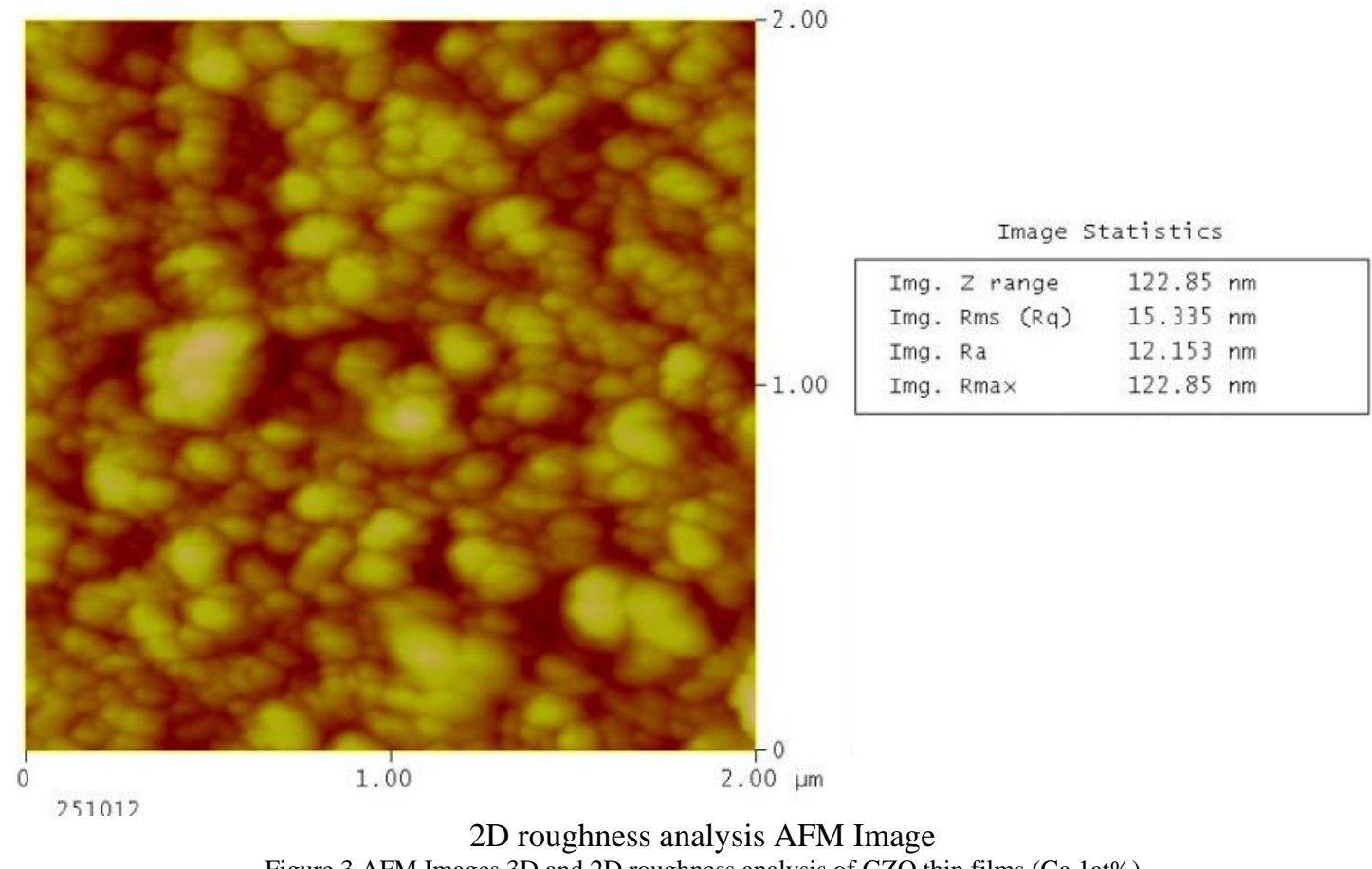

Figure 3 AFM Images 3D and 2D roughness analysis of GZO thin films (Ga 1at\%)

\subsection{Acetone sensing properties}

\section{(a) Effect of temperature and Acetone concentration}

Fig. 5.13 shows the response value for Ga-doped $\mathrm{ZnO}$ sensors to $1000 \mathrm{ppm}$ acetone at different operating temperature. It can be seen that the response of sensors varies with not only the amounts of the $\mathrm{Ga}$ addition but also the operating temperature. All the sensors display a maximum response value at the operating temperature of $573 \mathrm{~K}$. At the optimum temperature, the response to 1000 ppm acetone increased from $15 \%$ to $23 \%$ as $\mathrm{Ga}$ at $\%$ is increased from 1 at $\%$ to 3 at $\%$ and further increase in $\mathrm{Ga}$ doping in $\mathrm{ZnO}$ response decreased. When the operating temperature increases further, the response value decreases, which may result from the competing desorption of the chemisorbed oxygen. It reveals that the 3 at $\%$ Ga-doped $\mathrm{ZnO}$ sensor has much higher response value than the other sensors.

Fig. 5.14 shows the gas response as a function of Acetone concentration at $573 \mathrm{~K}$. The figure reveals that the response increased from $12 \%$ to $23 \%$ as the Acetone concentration increased from 250 to $1000 \mathrm{ppm}$. However, at higher Acetone concentrations the increase in gas response value was gradual and decreased for Acetone concentrations more than $1000 \mathrm{ppm}$. The response of a sensor depends on removal of adsorbed oxygen molecules by reaction with a target gas and generation of electrons. An increase in gas concentration increases the surface reaction due to a larger surface coverage. 


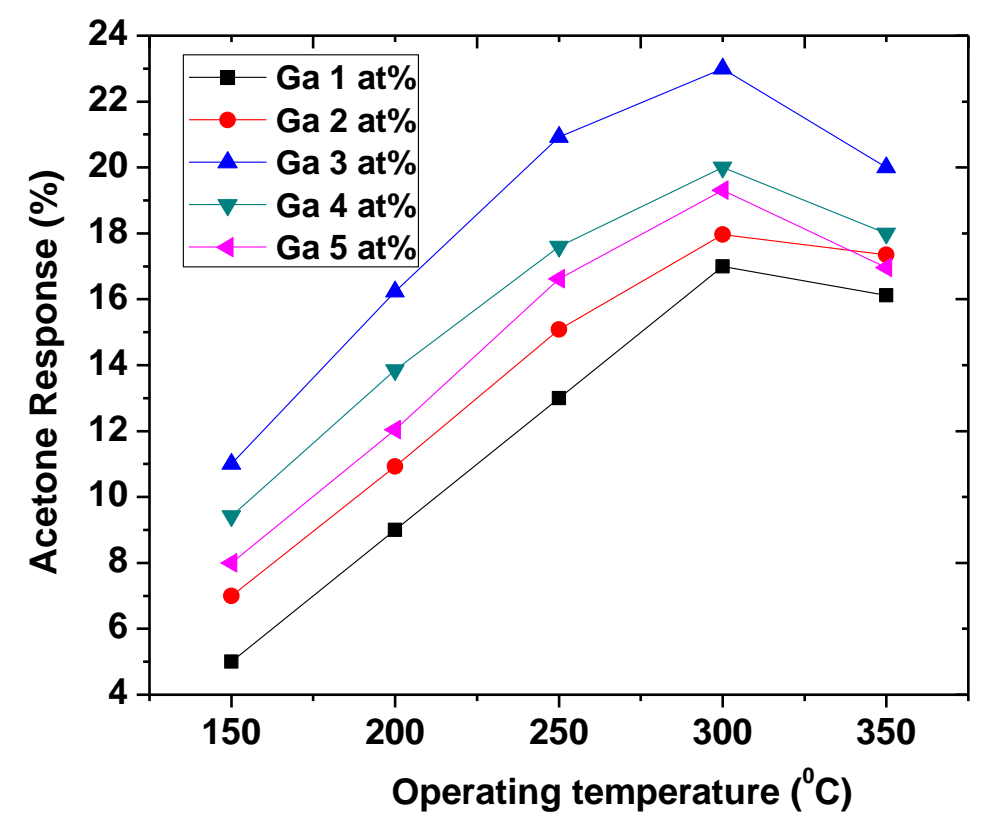

Figure 3: The variation of Acetone response of $\mathrm{Ga}: \mathrm{ZnO}$ film for different $\mathrm{Ga}$ at $\%$ to $1000 \mathrm{ppm}$ Acetone at different temperatures.

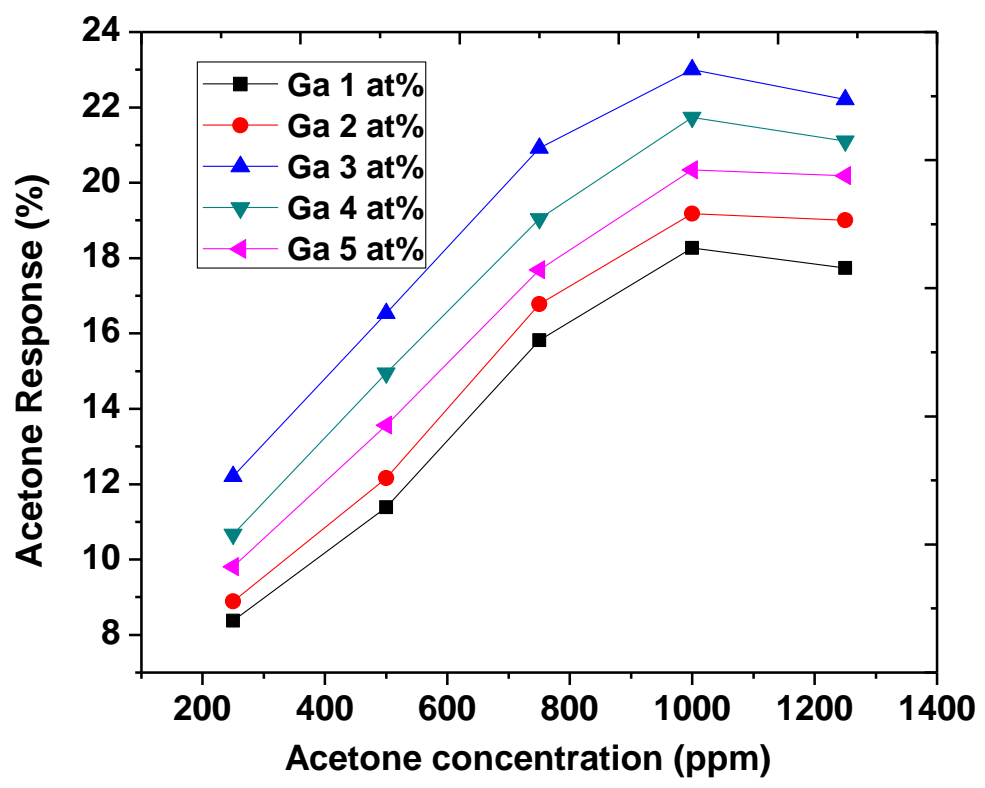

Figure 4: The variation of Acetone response of Ga: $\mathrm{ZnO}$ film to different Acetone concentrations

\section{CONCLUSIONS}

The Ga:ZnO thin films were deposited on amorphous glass substrates using spray pyrolysis technique. The XRD patterns of these samples are of wurtzite hexagonal $\mathrm{ZnO}$. It is also observed from SEM micrographs that grains are small and distributed uniformly throughout the surface. From the AFM images the surface roughness increases as dopant concentration $\mathrm{Ga}$ increases from $1 \%$ to $3 \%$. The response to $1000 \mathrm{ppm}$ acetone increased from $15 \%$ to $23 \%$ as Ga at $\%$ is increased from 1 at $\%$ to 3 at $\%$ and further increase in $\mathrm{Ga}$ doping in $\mathrm{ZnO}$ response decreased.

\section{REFERENCES}

[1] T. Minami, Semicond. Sci. Technol. 20 (2005) S35.

[2] H.J. Ko, Y.F. Chen, S.K. Hong, H. Wenisch, T. Yao, D.C. Look, Appl. Phys. Lett. 77 (2000) 3761.

[3] X. Yu, J. Ma, F. Ji, Y. Wang, C. Cheng, H. Ma, Appl. Surf. Sci. 245 (2005) 310.

[4] Min-Jung Lee, Jinhyong Lim, Jungsik Bang, Woong Lee, JaeMin Myoung, Applied Surface Science 255 (2008) 3195-3200

[5] B.Y. Oh, M.C. Jeong, J.M. Myoung, Appl. Surf. Sci. 253 (2007) 7157.

[6] S. Shirakata, T. Sakemi, K. Awai, T. Yamamoto, Thin Solid Films 451-452 (2004) 212.

[7] T. Yamamoto, T. Sakemi, K. Awai, S. Shirakata, Thin Solid Films 451-452 (2004) 439. 
[8] Y. Suzuki, F. Niino, K. Katoh, J. Non-Crystalline Solids 218 (1997) 30.

[9] M. A. Kaid, A. Ashour, Applied Surface Science, 253 (2007) 3029.

[10] T. P. Rao, M.C.S. Kumar, J. Alloys and Compd. 506 (2010) 788.

[11] M.A. Barote , A.A.Yadav, E.U.Masumdar, Physica B406 (2011) 1865.

[12] R. A. Smith, Semiconductors, Academic Publishers, Culcutta, 1989, pp-461-463.

[13] C.Y. Yen, S.R. Jian, G.J. Chen, C.M. Lin, H.Y. Lee, W.C. Ke, Y.Y. Liao, P.F. Yang, Y.S. Lai, J.S.C. Jang, J.Y. Juang, Appl. Surf. Sci. 257 (2011) 7900.

[14] Szu-Ko Wang, Ting-Chun Lin, Sheng-Rui Jian, Jenh-Yih Juang, Jason S.-C. Jang, Jiun-Yi Tseng, Applied Surface Science 258 (2011) 1261- 1266. 